\title{
EDITORIAL \\ Funding for gun violence research: the importance of sustained advocacy by academic pediatricians
}

\author{
Pediatric Research (2020) 87:800-801; https://doi.org/10.1038/s41390- \\ 020-0798-5
}

Gun violence is pervasive in the United States, so common that it can often fade into the background. The oft-cited statistics are familiar: the rate of gun deaths in the United States far exceed that of other high-income countries and more than 35,000 individuals die by guns each year. ${ }^{1}$ Children are particularly impacted by this epidemic; gun violence is the second leading cause of death in children and far exceeds deaths from cancer. ${ }^{2}$ There have been over 100 school shooter incidents in each of the past 2 years, and active shooter drills in schools are now commonplace, potentially producing trauma themselves. ${ }^{3}$ Student survivors from the shooting in Parkland have helped bring a new focus to the need for government action to address gun violence with their \#NeverAgain movement. ${ }^{4}$ While these mass shootings garner national media attention, children also bear the burden of the daily toll of gun violence in their communities. Although there has been some success in individual states, efforts at implementing initiatives such as universal background checks and banning assault weapons have failed at the federal level, despite widespread public support. Federal resistance has long extended to the arguably less controversial need to better study and understand gun violence. However, but a recent development in Congress offers a promising opportunity to revive this important work.

Barriers to conducting gun violence research have been maintained by Congress over the past 20 plus years. The National Rifle Association first raised their concerns to Congress about gun violence research after the New England Journal of Medicine published an article in 1993 entitled "Gun ownership as a risk factor for homicide in the home"; the study was funded by the US Centers for Disease Control and Prevention (CDC). ${ }^{5}$ In 1996, Congress included language (often referred to as the Dickey amendment) in an appropriation bill that stated: "none of the funds made available for injury prevention and control at the CDC may be used to advocate or promote gun control.." ${ }^{\prime \prime}$ While this language did not explicitly prohibit gun violence research, the same bill transferred money from gun violence research to the study of traumatic brain injury, leading to a chilling effect on these research efforts. The message was clearly received by CDC and investigators and gun violence research was effectively curtailed. The Dickey amendment was expanded in 2011 to include other entities within the US Department of Health and Human Services, including the National Institutes of Health, further discouraging research into gun violence.

Over the years, it became clear that restrictions on gun violence research could be counterproductive in the overall effort to improve public health. In 2012, former Representative Jay Dickey, the author of the original language, publicly began advocating for an evidence-based approach to gun violence and the resumption of research. ${ }^{7}$ In 2018, Congress included language in an explanatory report accompanying the spending bill to clarify that the Dickey amendment did not prohibit research: "While appropriations language prohibits the CDC and other agencies from using appropriated funding to advocate or promote gun control, the Secretary of Health and Human Services [Alex Azar] has stated the CDC has the authority to conduct research on the causes of gun violence." However, the bill did not specifically appropriate dedicated funding for gun violence research. It became clear to research advocates that the Dickey amendment was no longer the barrier it was perceived to be, but that meaningful federal investments in gun violence research would require congressional direction in the form a specific line item in a spending bill.

The tragedy in Parkland and the student activism that followed reinvigorated the push for national policy responses to the gun violence epidemic. Funding for gun violence research emerged as a policy effort that could attract bipartisan support. While research into gun violence had long been a priority of the pediatric community, pediatric advocates seized on the opportunity to advance these efforts in 2018. The Pediatric Policy Council (PPC), a public policy collaborative made up of four academic pediatric groups-the Academic Pediatric Association, the American Pediatric Society, the Association of Medical School Pediatric Department Chairs, and the Society for Pediatric Researchdecided to prioritize gun violence research funding as a major advocacy issue. The PPC, working with the American Academy of Pediatrics and other advocacy groups, was instrumental in developing a funding proposal of US\$50 million for this research, which was supported by an additional 160 medical and public health groups. The PPC also developed a list of important associated research topics that required federal investments, which was shared with policymakers. The list included topics such as messaging to promote safe firearm storage, the prevention of teen suicide by firearm, the consumption of violent media, and the identification of children at risk for participating in school violence.

The mid-term congressional elections of 2018-which saw a number of NRA-backed members of Congress lose to challengers who prioritized gun violence policies in their platformsserved as a turning point in the endeavor. The PPC joined with others in intensive advocacy activities to encourage Congress to view gun violence as a public health issue and fund it as such. The spending bill passed by the House of Representatives in June 2019 was historical in that it included a US\$50 million appropriation for gun violence research, evenly split between CDC and NIH.

While the Senate did not act on its own on the issue, the final fiscal year 2020 spending package signed into law at the end of 2019 included a US\$25 million appropriation for "firearm injury and mortality prevention," similarly divided between the two research agencies. Congress specified that this firearm-related research should address "underlying causes and evidence-based methods of prevention of injury, including crime prevention." The language also stipulated that grantees "be required to fulfill requirements around open data, open code, pre-registration of research projects, and open access to research articles consistent 
with the National Science Foundation's open science principles". ${ }^{8}$ The Dickey amendment was also included in the appropriation bill as it had been for the previous two decades.

The CDC and the NIH are now tasked with moving ahead with plans to conduct this research with its new congressional appropriation. Public scrutiny of this research will undoubtedly be intense, and Congress will have to act anew every year to ensure this funding continues. Continued advocacy will be necessary to ensure that this funding is not eliminated again as it once was. Advocacy has long been a core value in pediatrics and all our academic societies have incorporated advocacy as a founding principle. Academic pediatricians have proven to be compelling advocates because they prioritize the well-being of children, are viewed as unbiased, and base their advocacy in science. The success of restoring gun violence research should serve as an example to the pediatric academic community that sustained advocacy for children and for research is necessary and effective, no matter how long it takes.

\section{AUTHOR CONTRIBUTIONS}

All authors provided meaningful contributions to this manuscript.

\section{PEDIATRIC POLICY COUNCIL (PPC)}

Scott Denne, MD, Chair, Pediatric Policy Council, Indianapolis, IN, USA; Shale Wong MD, MSPH, PPC Representative, Academic Pediatric Association, Aurora, CO, USA Jean Raphael, MD, MPH, PPC Representative, Academic Pediatric Association, Houston, TX, USA; Jonathan Davis, MD, PPC Representative, American Pediatric Society, Boston, MA, USA; DeWayne Pursley, MD, MPH, PPC Representative, American Pediatric Society, Boston, MA, USA; Tina Cheng, MD, MPH, PPC Representative, Association of Medical School Pediatric Department Chairs, Baltimore, MD, USA; Michael Artman, MD, PPC Representative, Association of Medical School Pediatric Department Chairs, Kansas City, MO, USA; Shetal Shah, MD, PPC Representative, Society for Pediatric Research, Valhalla, NY, USA; Joyce Javier, MD, MPH, MS, PPC Representative, Society for Pediatric Research, Los Angeles, CA, USA.

\section{ADDITIONAL INFORMATION}

Competing interests: The authors declare no competing interests.

Publisher's note Springer Nature remains neutral with regard to jurisdictional claims in published maps and institutional affiliations.

Scott C. Denne ${ }^{1}$, James Baumberger ${ }^{2}$ and Matthew Mariani ${ }^{2}$ the Pediatric Policy Council

${ }^{1}$ Department of Pediatrics, Indiana University, Indianapolis, IN, USA and ${ }^{2}$ American Academy of Pediatrics, Washington, DC, USA

Correspondence: Scott C. Denne (sdenne@iu.edu)

\section{REFERENCES}

1. McLean, R. M. et al. Firearm-related injury and death in the United States: a call to action from the nation's leading physician and public health professional organizations. Ann. Intern. Med. 171, 573-577 (2019).

2. Cunningham, R. M., Walton, M. A. \& Carter, P. M. The major causes of death in children and adolescents in the United States. N. Engl. J. Med. 379, 2468-2475 (2018).

3. K-12 Shooting database. https://www.chds.us/ssdb/incidents-by-year-2010-present/. Accessed 13 January 2020.

4. Wong, S. L. \& Raphael, J. L. Are you listening to our children: empowering youth advocates. Pediatr. Res. (2020). https://doi.org/10.1038/s41390-019-0743-7.

5. Kellermann, A. L. et al. Gun ownership as a risk factor for homicide in the home. $N$. Engl. J. Med. 329, 1084-1091 (1993).

6. Jamieson, C. Gun violence research: history of the federal funding freeze. https://www.apa.org/science/about/psa/2013/02/gun-violence. Accessed 13 January 2020.

7. Dickey, J. \& Rosenberg, M. We won't know the cause of gun violence until we look for it. 2012. https://www.washingtonpost.com/opinions/we-wont-know-the-causeof-gun-violence-until-we-look-for-it/2012/07/27/gJQAPfenEX_story.html. Accessed 13 January 2020.

8. Joint Explanatory Statement accompanying H.R. 1865 - the Further Consolidated Appropriations Act, 2020, 116th Congress. Became Public Law 116-94 on 20 December 2019. 